\title{
EDUCAÇÃO ESTÉTICA E EDUCAÇÃO FÍSICA: A DANÇA NA FORMAÇÃO DE PROFESSORES
}

\author{
LÁzaro Moreira Gomes JúNIOR*** \\ LeNIR Miguel De LiMA***
}

\section{RESUMO}

Investigar a visão do futuro professor de Educação Física, em relação ao ensino da dança, é a tônica deste trabalho. A pesquisa faz uma análise sobre a constituição de corpo na modernidade, além de salientar a necessidade de uma educação que valorize não apenas o universo da racionalidade, como também o da sensibilidade, tendo em vista a manutenção de nossa identidade cultural e a construção de um saber universal. Discutem-se questões sobre a dança na educação, na perspectiva de torná-la libertadora e transformadora.

PALAVRAS-CHAVE: Dança - Educação Estética - Formação de professores.

\section{INTRODUÇÃO}

A dança acompanha o homem desde os tempos primordiais. Du presente, assumindo as mais variadas funções. Acredito que todo ser humano, se nunca dançou, um dia há de dançar. No entanto, se a dança tem essa ligação tão profunda com o homem, por que ela é negada? Por que professores de Educação Física, quando têm de trabalhar com a dança, acham uma forma de substituí-la por um outro conteúdo?

Minha orientadora relatou, durante o período de realização de minha monografia, que, numa de suas aulas de dança na Faculdade de Educação Física da Universidade Federal de Goiás, os alunos lhe diziam que nunca teriam problema em trabalhar com esta

\footnotetext{
* Artigo proveniente de pesquisa realizada como projeto de final de curso.

** Licenciado em Educação Física pela Universidade Federal de Goiás.

***Professora na Faculdade de Educação Física da Universidade Federal de Goiás, mestre em Educação Brasileira-FE/UFG e doutoranda em Filosofia na Faculdade de Valencia, Espanha.
} 
disciplina em suas aulas. Porém, ao aprofundar o diálogo, constatou que eles só não teriam problemas porque jamais pretendiam trabalhar com essa disciplina como conteúdo da Educação Física.

Esse fato, associado a vários outros, me direcionou para a compreensão imediata de que há uma parcela considerável de professores de Educação Física que vem negligenciando a disciplina Dança em suas aulas e, além disso, tratando-a de forma preconceituosa. Esse foi o pontapé inicial para a realização deste trabalho, que constou de um levantamento bibliográfico e da realização de entrevistas com alunos do $1^{\circ}$ e do $4^{\circ}$ ano do curso de Educação Física da UFG, no ano de 2002.

Como a dança, patrimônio cultural constituído e construído pelo homem, pode ser tão discriminada dentro da Educação Física, sobretudo depois das duas últimas décadas, que trouxeram novos conceitos de educação, centralizados na formação crítica?

Para compreender melhor o quadro que se estabelece, é preciso desviar um pouco os olhares e detectar a visão de corpo que temos na contemporaneidade.

\section{CONSTITUIÇÃO E CONTROLE DO CORPO NA MODERNIDADE}

Temos hoje uma visão de corpo em que este se apresenta individualizado, fragmentado e uniformizado. A própria dança traz exemplos dessas características. Em algumas composições coreográficas - principalmente as oriundas da indústria cultural, ${ }^{1}$ como o axé ${ }^{2}-$ essa visão de corpo fica bastante clara. Salvo algumas exceções, as pessoas dançam sem estabelecer o contato corporal entre si. Isso demonstra um processo de individualização acentuado, em que a coreografia é a mesma para todos, padronizando o movimento humano como se todos fossem um batalhão de robôs. E muitas das vezes se dança apenas com as partes do corpo, como na dança do bumbum, dança do dedinho e etc.

$\mathrm{O}$ corpo na modernidade tornou-se cada vez mais corpo, e a alma cada vez mais alma. E onde se encontra a origem disso? Devemos voltar até a Idade Média, período marcado por um enorme controle social imposto pela Igreja, que, com os seus dogmas, estabe- 
lecia verdades absolutas, imprimindo ao corpo uma série de tabus. Na Europa feudal, "ver o corpo é ver o feio e, por isso, a vergonha de mostrá-lo" (Silva, 1999, p. 25-26).

A dança naquele período passou por momentos muito difíceis, pois a Igreja, que no início ainda aceitava essa manifestação cultural, passou a persegui-la, como sendo fruto do pecado: "As danças [...] foram [...] tenazmente combatidas pela Igreja por causa do seu visível conteúdo pagão, demasiadamente ligado às velhas religiões" (Mendes, 1987, p. 17).

A situação por que passava o mundo ocidental ocasionou uma série de mudanças de ordem socioeconômica. Como resposta aos abusos do clero, veio o período definido como Renascimento.

Primeiro grande movimento cultural burguês dos tempos modernos, o Renascimento enfatizava uma cultura laica (não-eclesiástica), racional e científica, sobretudo não-feudal. Entretanto embora tentasse sepultar os valores da Igreja Católica, apresentou-se como um entrelaçamento dos novos e antigos valores, refletindo o caráter de transição do período. Buscando subsídios na cultura greco-romana, o Renascimento foi à eclosão de manifestações artísticas, filosóficas e científicas do novo mundo urbano e burguês. (Vicentino, 1993, p. 123)

Nomes importantes contribuíram para que esse período se concretizasse como um dos mais brilhantes da produção artística mundial. Dante Alighieri, com sua obra-prima, a Divina Comédia, foi o precursor do movimento, que, ainda na literatura, teria Petrarca e Boccaccio; nas artes plásticas, Macassio, Botticelli, Leonardo da Vinci, Rafael, Michelangelo e Erasmo de Rotterdam; e, na dramaturgia, os espanhóis Tirso de Molina, Lope de Veja e Miguel de Cervantes. Em Portugal apareceram Gil Vicente e Luís Vaz de Camões, e na Inglaterra surgiu aquele que seria considerado o maior de todos os dramaturgos - William Shakespeare.

Não se pode esquecer que foi também na Renascença que apareceu Martinho Lutero, autor da reforma protestante que traria modificações internas e externas para a Igreja.

Impulsionado pelo renascimento artístico, veio o científico. Nicolau Copérnico questionou o sistema de orientação dos astros, 
retirando a idéia da Terra como o centro do universo e colocando nele o sol. Nascia assim o heliocentrismo, concluído por Galileu Galilei um século mais tarde.

Dentro desse panorama de efervescência cultural e científica, a razão se tornaria o cerne das discussões, constituindo o alicerce do mundo. A racionalidade foi proclamada a via única das dimensões humanas. $\mathrm{O}$ homem ficou então enclausurado nos limites da razão.

A ideologia cientificista impregnou o período renascentista, levando a sociedade a grandes mudanças e a ser vista como um organismo vivo. Foi criado um universo de paradigmas matemáticos e mecânicos, orientadores do desenvolvimento. A partir daquele momento, "tudo [podia] ser medido, classificado, comparado, definido e generalizado a partir da descoberta constante de leis" (Soares, 1998, p. 19). O surgimento da sociedade moderna se deu, portanto, exclusivamente pelo viés da racionalidade, e dele originouse a luta do homem consigo mesmo e com a natureza. Surgiu então o indivíduo, característica marcante de nossos dias.

A Modernidade é o momento de culminância de um processo em que não só se encontra a separação entre ser humano e natureza, como também a separação, ainda que formal, entre todos os seres humanos que se tornam, desde então, indivíduos. (Silva, 1999, p. 8)

O fim de algumas leis estabelecidas anteriormente faz recair sobre o corpo um grande interesse. As aulas públicas de anatomia se tornam verdadeiros espetáculos. O corpo é dividido em partes e estudado a fundo, para que se descubram os seus segredos e os meios de controlá-lo.

A transformação do corpo humano em algo que pode ser mensurável é, também, sua transformação em algo que pode ser dominado. Essa dessacralização do corpo aponta para sua ambigüidade no interior da cultura ocidental: é importante enquanto fonte de experiência, mas é, também, o corpo que se desvaloriza na medida em que se pode mexer nele e alterá-lo. É, talvez, aqui que se pode localizar o início do corpo como construção humana, gênese que chega ao seu auge, atualmente, com a genética e a medicina estética. (Silva, 1999, p. 30) 
O corpo é dominado no campo biológico e, posteriormente, no social. Controla-se o divertimento do povo, em especial aquele proporcionado pelos artistas circenses de rua.

A razão básica do crescente receio era a constatação de que o universo próprio do circo apresentava uma total urgência de utilidades. O corpo ali exibido em movimento constante despertava o riso, o temor e, sobretudo, a liberdade. A atividade livre e lúdica, encantatória, do acrobata devia ser redesenhada no imaginário popular. Em seu lugar [...] nasceriam as séries de exercícios físicos, pensados, exclusivamente, a partir de grupos musculares e de funções orgânicas, a serem aplicados com finalidades específicas, úteis, e não como mero entretenimento. Instalava-se também, com força nunca antes vista, um desejo de controlar o divertimento do povo, o tempo fora do trabalho. (Soares, 1998, p. 23-24)

O corpo torna-se então uma máquina à disposição dos interesses das classes dominantes. Essa característica aumenta significativamente com o passar do tempo.

A manipulação do corpo foi, progressivamente, assumindo proporções cada vez mais graves, com a expansão do sistema capitalista e com o desenvolvimento da tecnologia: os movimentos corporais tornaram-se instrumentalizados, como se pode observar, por exemplo, na indústria, ao dissociar os movimentos corporais em partes isoladas para aumentar a produção. (Gonçalves, 2001, p. 17)

E onde esteve a dança neste momento?

A dança não ficou na contramão da história e assumiu as características peculiares da época. Como a tônica daquele momento era a racionalidade, esta foi impressa à dança, que se profissionalizou com o surgimento da Academia Real de Balé na França, no século XVII.

Tal fato representou um marco, pois promoveu a participação da mulher nos espetáculos de dança, até então executados só por homens. Em meados do século XIX a ascensão feminina atingiu o auge com o desenvolvimento da técnica da ponta de pés, fruto do estudo fragmentado do corpo do bailarino.

No entanto, a dança perdeu um pouco a sua essência e buscou a perfeição técnica, que se "tornou um fim em si mesmo: o 
essencial a partir daí era a clareza, o equilíbrio e a ordem, mesmo que isso levasse à rigidez. A arte se separava da vida e de sua expressão" (Garaudy, 1980, p. 32).

Fátima (2001, p. 41) acrescenta: "O bailarino passou a ser um virtuose, um especialista de uma arte cujo interesse era a performance técnica num movimento de rebeldia dos que queriam uma arte expressando a humanidade, a vida".

A dança assim se distanciava do povo cada vez mais. Associada ao virtuosismo dos saltos e piruetas dos bailarinos, ela perdia um pouco de seu poder expressivo, de sua capacidade de trabalhar o lúdico, o cênico. Usada também com fins pedagógicos, como os propostos por Amoros, ${ }^{3}$ a dança na educação ficou reduzida às

danças pírricas ou militares, e às danças de sociedade mais ou menos desenvolvidas, de acordo com as aplicações que o aluno deverá dar a elas. A dança cênica ou teatral pertence ao funanbulismo e não pode entrar em nosso projeto. (Amoros, apud Soares, 1998, p. 40)

A dança assumia, então, a característica de controle dos movimentos do corpo, uma vez que não era permitida ao homem qualquer manifestação de cunho lúdico e emocional. Só eram aceitos os movimentos de preparação para o trabalho, dentro dos padrões estabelecidos pela modernidade, de acordo com o projeto de uma sociedade burguesa que necessitava controlar as atividades das demais camadas sociais.

Tal característica assumida pela dança encontra-se presente na contemporaneidade. Relegada a um segundo plano, a dança na educação preocupa-se em preparar os alunos não para um posicionamento crítico diante da realidade, mas para decorar um arsenal de fórmulas e cálculos, necessários no vestibular.

Falar em dança na educação é falar sobre uma educação estética, entendida aqui como "um processo de sensibilização do ser. Trata-se de permitir a formação de parâmetros através de experimentação de uma relação com o sensível" (Medeiros, 2002, p. 3).

Esse processo de sensibilização não passa pela simples visão de uma apreciação estética, mas também deve ser compreendido como uma tentativa de acrescentar ao universo da racionalidade 
novos valores, ampliando assim a possibilidade de uma educação crítica, como aponta Bracht (2001, p. 77):

é preciso considerar a educação estética ou da sensibilidade como elemento importante do que poderíamos chamar de criticidade [...]. Isso significa [...] fazer com que reformulemos nosso conceito de criticidade, ampliemos nosso conceito de razão, englobando as dimensões estéticas e éticas.

Não se pretende aqui extinguir a dimensão racional do mundo, pois ela deve estar presente, direcionando o planejamento de todo processo educacional. Ao contrário, parte-se do pressuposto de que o homem se desenvolve no entrelaçamento do racional com o emocional; assim, tendo a dança como conteúdo da Educação Física teremos um canal aberto de comunicação entre esse dois pólos.

O conceito de criticidade, pelo viés da sensibilidade, da subjetividade, segundo Kunz (2000, p. 109), pode ser entendido como “... processo por meio do qual o homem se desenvolve no contexto social concreto, numa relação tensa entre um 'ser social' e um 'ser individual' ".

O equilíbrio entre os pólos racional e emocional pode levar a uma educação crítica, que tenha de um lado a racionalidade, base da sociedade moderna ocidental, e de outro a possibilidade de mantermos viva nossa identidade cultural, pelo caminho da experimentação estética: ${ }^{4}$ "ler e julgar a qualidade das imagens produzidas por artistas ou do mundo cotidiano que nos cerca faz parte de entendermos e sermos mais críticos em relação a nossa herança cultural" (Marques, 1999, p. 36).

Também a dança pode contribuir para a construção de uma sociedade que não desconsidera um conhecimento em detrimento de outro. Por que, então, alunos de licenciatura em Educação Física não pretendem incluir a dança como conteúdo de suas aulas?

Para tentar esclarecer tais inquietações, algumas entrevistas foram realizadas.

Do universo de entrevistados, $75 \%$ não tiveram contato com a dança nas aulas de Educação Física, durante a vida escolar. Isso demonstra que, mesmo depois de todo o processo de mudança pelo 
qual a Educação Física vem passando, a dança continua sendo desprivilegiada, assim como todo conhecimento de cunho um pouco mais subjetivo.

As entrevistas revelam também a manutenção de algumas práticas que se prorrogam por muitos anos na Educação Física, em que o laissez-faire estabelece a tônica das aulas:

A professora deixava a gente numa sala de aula e aí falava: criem. A gente tinha que montar uma coreografia ... só. Eu também não queria que ela soltasse a gente, falasse "criem" e pronto. Ela não dava [explicações], não era direcionado, entendeu? Ela não dava nenhum subsídio para você criar. Ela deixava você na sala e, quando voltava, você tinha que ter alguma coisa; até que eu cansei de fazer essas aulas de dança. (Entrevista 8)

Outro ponto levantado foi de que um ano para o conteúdo "dança" na licenciatura é pouco, principalmente se o aluno não teve contato sistematizado com qualquer tipo de dança. $\mathrm{O}$ ensino realizado de forma fragmentada faz que os alunos não consigam realizar os nexos entre as disciplinas do currículos.

Uma das entrevistas relata um certo medo com relação ao conteúdo "dança", por parte dos professores: "Eu acho que, pros professores, ainda falta muito pra eles terem elementos pra trabalhar. Muitos não incluem, mas talvez por medo de não dar conta de passar todos os conteúdos de dança" (Entrevista 2).

Sendo a dança um conteúdo curricular novo é normal surgir um certo receio, porém algumas entrevistas apontam uma série de fatores que podem esclarecer o porquê desse medo, como, por exemplo, a falta de compromisso por parte dos alunos: "Eu não daria... por não saber e por não ter me dedicado à matéria dança, que foi vista no $1^{\circ}$ ano" (Entrevista 11). "E quando teve, eu achei, assim, muito mais descontração que aprendizado" ( Entrevista 4 ).

Essas duas respostas direcionam a dança para uma situação de marginalidade, considerando-a supérflua e de segundo plano, opinião partilhada por alguns autores.

A dança tem sido considerada supérflua, por um lado, porque não abarca, com a racionalidade do saber necessário, a produção da sociedade in- 
dustrial; por outro lado, porque não instrumentaliza o fazer necessário a ser mão-de-obra barata, nessa mesma sociedade. (Fiamoncini \& Saraiva, 1998, p. 95)

Um dos entrevistados não inclui a dança como conteúdo em suas aulas, por não achá-la motivante, e estabelece uma divisão por gênero:

... não é uma disciplina motivante para os alunos [homens...], só as [alunas] mulheres preferencialmente vêem a dança enquanto conteúdo agradável. Já para os homens seria uma coisa desagradável e ninguém gostaria de fazer, e por isso, eu não iria trabalhar com ninguém essa disciplina. (Entrevista 4 )

O fator preocupante é que, em pleno século XXI, ainda existam alunos que acreditam que a dança é coisa de mulher. " $\mathrm{Na}$ minha opinião sim, porque a mulher tem mais sensibilidade, mais movimento no corpo" (Entrevistado 1).

Devemos lembrar que, após o desenvolvimento da técnica da ponta de pés, a representatividade feminina, no decorrer da história, sobressaiu à masculina no mundo da dança. Esse conceito se solidificou, e a dança veio a servir até de instrumento de luta feminista.

O recurso da dança também permitiu às mulheres controlar e sublimar sua sexualidade, que fora dominada pelos homens. Para ir adiante numa vanguarda de terreno inexplorado, algumas mulheres precisavam ter uma dedicação de freira. Outras mulheres respeitáveis na dança, de classe média e alta, tinham casos de amor dentro e fora do casamento, para mostrar seu novo senso de igualdade social e sexual. (Hanna, 1999, p. 197)

O movimento corporal, como parte da construção social, não pertence a um ou outro gênero. Alguns dos entrevistados já tiveram essa percepção e, questionados sobre a inclusão da dança em suas aulas, responderam afirmativamente.

Eu creio que sim porque... depois das aulas de dança que tivemos houve uma interação maior, a turma se tornou mais unida. Acho isso importante. (Entrevista 7) 
Incluiria sim, porque eu vejo que os alunos, ao mesmo tempo que estão numa sala, estão muito distante entre si. Eu daria uma aula de dança para melhorar a integração entre os próprios alunos. (Entrevista 10)

Ou seja, a capacidade de integração e de união, possibilitando o desenvolvimento de um trabalho coletivo, é vista como justificativa para a inclusão da dança nos planos de aula de Educação Física. Ela se apresenta como um caminho de inversão da sociedade individualizada, manifesta no corpo.

A força do grupo, uma vez coordenada e ritmada, mostra-se superior à soma das forças individuais dos participantes. $\mathrm{O}$ homem adquire assim um novo poder e toma consciência dessa transcendência da comunidade em relação aos indivíduos. (Garaudy, 1980, p. 19)

Outro ponto de fundamental importância para o qual a dança pode contribuir é a capacidade de desenvolvimento da criatividade. Quando associadas a uma dança livre, a imaginação e a criatividade são

pontos fundamentais em um projeto de educação que tenha como objetivo a formação de pessoas que não apenas aprendam os conhecimentos elaborados pela humanidade como verdades absolutas e imutáveis, porém, que saibam refletir e que se sintam capazes de interferir sobre esses conhecimentos, reelaborando-os. (Fiamoncini \& Saraiva, 1998, p. 98)

Para finalizar, devo confessar que foi a perspectiva de inserir definitivamente a dança nos planos de aula elaborados pelos professores de Educação Física que pautou o desenvolvimento deste trabalho. Mas uma dança associada à discussão e reflexão dos conhecimentos, tanto racionais quanto emocionais, demonstrados por uma experimentação estética. A Educação Física precisa, portanto, estreitar mais seus laços de diálogo com outros campos de conhecimento. Hoje, isso é ainda um sonho. Mas, se concretizado, ele pode apresentar-se como uma forma criativa de interferir na sociedade, utilizando a dança como elemento transformador e libertador do homem, pois ela surge no cenário escolar como 
um processo criativo, através do qual [...], o ser humano poderá emancipar-se, porque criatividade possibilita a independência (reflexão), a liberdade (decisão) e a autonomia (criação) para modificar o mundo e, também, emancipar a sociedade (criar novas e melhores condições sociais para todos). (Nanni, apud Ternes,1997, p. 59)

Sonhamos ver um dia alunos, professores e toda a comunidade exercendo com dignidade o seu direito à cidadania. A dança será uma aliada na busca de dias melhores para - conforme Milton Nascimento e Fernando Brandt, na canção "Maria, Maria" - "uma gente que ri quando deve chorar, e não vive, apenas agüenta". Mas para que isso ocorra "é preciso ter força, é preciso ter raça, é preciso ter gana sempre [...] é preciso ter manha, é preciso ter graça, é preciso ter sonhos sempre".

\title{
Aesthetic Education and Physical Education: Dance in Teacher Development
}

\begin{abstract}
Investigating the views of future P. E. teachers in relation to the teaching of dance. This is the aim of this study, which analyzes the constitution of the body in our contemporary times, searching for an education that values not only the rational universe, but also the sensitive world, one that stands for the keeping of our cultural identity and the building of universal knowledge, discussing questions about dance in education, in the perspective of turning dance into a freeing and transforming experience.
\end{abstract}

KEY WORDS: Dance - Aesthetic education - Teacher's formation.

Educación Estética y Educación Física: La danza en la Formacion de profesores

\section{RESUMEN}

Investigar la vision del futuro professor de Educación Física, en relación a la enseñanza de la danza, es la tónica de este trabajo, haciendo un análisis acerca de la constitución del cuerpo em la modernidad, buscando una educación que valorice no solamente el universo de la racionalidad, pero también el de la sensibilidad, em defensa del mantenimiento de nuestra identidad cultural y construcción de un conocimiento universal, discutindo cuestiones acerca de la danza en la educación, em perspectiva de hacerla libertadora y transformadora. PALABRAS CLAVES: Danza - Educación estética - Formación de profesores. 


\section{NOTAS}

1 O conceito de indústria cultural surge em 1947, criado pelos frankfurtianos, e trata da produção em série e da homogeinização e conseqüente deterioração dos padrões culturais. Isso vem reforçando a dominação técnica imposta pelo sistema, gerando a conformidade e impedindo a formação de indivíduos autônomos e independentes. Assim, seus produtos estão impregnados pela ideologia dominante, provocando o conformismo.

2 Segundo Prandi (2001), axé é a força-mestra dos orixás, a energia que orienta o mundo. No texto, a palavra é empregada para designar um estilo de dança de origem baiana muito utilizada pela indústria cultural.

3 Estudioso espanhol de formação militar, nascido em 1770, que utilizou a ginástica como um conjunto de normas e condutas morais, com um caráter ordenativo e disciplinador do homem.

4 Experimentação estética pode ser compreendida como a relação entre o sujeito e o objeto estético (obra de arte, teatro, dança etc.), estabelecida por um jogo em que o sujeito entra no mundo da obra, formulando assim novos conhecimentos. Através desse jogo o sujeito começa a compreender e a descobrir como o mundo pode ser e o que nós podemos ser (Aranha \& Martins, 1992).

\section{REFERÊNCIAS}

ARANHA, Maria Lúcia de Arruda; MARTINS, Maria Helena Pires. Temas de Filosofia. São Paulo: Moderna, 1992.

BRACHT, Valter. Saber e fazer pedagógico: acerca da legitimidade da Educação Física como componente curricular. In: CAPARROZ, Francisco Eduardo (Org.). Educação Física Escolar. Vitória: Ed. Proteoria, 2001.

FÁTIMA, Conceição Viana. Dança: linguagem do transcendente. 2001. Dissertação (Mestrado) - Universidade Católica de Goiás, Goiânia, 2001. 
FIAMONCINI, Luciana; SARAIVA, Maria do Carmo. Dança na escola: a criação e a co-educação em pauta. In: KUNZ, Eleonor (Org.). Didática da Educação Física. Ijuí: Ed. Unijuí, 1998.

GARAUDY, Roger. Dançar a vida. Tradução Antônio Guimarães Filho e Glória Mariane. Rio de Janeiro: Nova Fronteira, 1980.

GONÇALVES, Maria Augusta Salin. Sentir, pensar e agir: corporeidade e educação. 5. ed. Campinas: Papirus, 2001.

HANNA, Judith Lynne. Dança; sexo e gênero: signos de identidade, domesticação, desfio e desejo. Tradução de Mauro Gama. Rio de Janeiro, 1999.

KUNZ, Eleonor. Transformação didático pedagógica do esporte. Ijuí: Ed. Unijuí, 2000.

MARQUES, Isabel A. Ensino de dança hoje: textos e contexto. São Paulo: Cortez, 1999.

MEDEIROS, Bia. Corpos informativos. Disponível em: <www.corpos.org> Acesso em: 20 set. 2002.

MENDES, Mirian Garcia. A dança. 2. ed. São Paulo: Ática, 1987.

PRANDI, Reginaldo. Mitologia dos Orixás. São Paulo: Companhia das Letras, 2001.

SILVA, Ana Márcia. O corpo do mundo: reflexões acerca da expectativa de corpo na modernidade. Tese (Doutorado) - Universidade Federal de Santa Catarina, 1999.

SILVA, Ana Márcia. Elementos para compreender a modernidade do corpo numa sociedade racional. Caderno CEDES, São Paulo, SP, v. 19, n. 48, p. 7-29, ago.1999.

SOARES, Carmem Lúcia. Imagens da educação no corpo. Campinas: Autores Associados, 1998.

TERNES, Tais Raquel. A razão da dança sem razão: refletindo as possibilidades da dança na educação. In: CONGRESSO BRASILEIRO DE CIÊNCIAS DO ESPORTE, 10., 1997, Goiânia. Anais... Goiânia, 1997. v. 3, p. 55-64.

VICENTINO, Cláudio. História geral. 3. ed. São Paulo: Scipione, 1993. 
Recebido: maio de 2003 Aprovado: junho de 2003

Endereço para correspondência Lázaro Moreira Gomes Júnior Condomínio Panorama Park, Bl-F3 Ap. 301 Urias Magalhães

Goiânia-GO CEP: 74565-070 